\title{
Corsarios españoles en el Golfo de Honduras, 1713-1763 ${ }^{1}$
}

\section{Spanish Corsairs in the Gulf of Honduras, 1713-1763}

\author{
RAFAL REICHERT \\ Centro de Estudios Superiores de México y Centroamérica, \\ Universidad de Ciencias y Artes de Chiapas
}

\begin{abstract}
Resumen: El objetivo principal de este artículo es la presentación de las actividades corsarias en el Golfo de Honduras entre los años 1713 y 1763, una época en que la Gran Bretaña recibió el privilegio de comerciar con Hispanoamérica a través del Asiento de negros y el navío de permiso. Tal acontecimiento provocó el desarrollo del contrabando en diferentes partes del Gran Caribe, como por ejemplo en la costa atlántica de la Capitanía General de Guatemala. El problema fue detectado pronto por las autoridades metropolitanas, quienes rigurosamente comenzaron a combatir el comercio ilícito otorgando a los gobernadores indianos el poder para expedir patentes de corso. A través de los estudios historiográfico y archivístico fue posible encontrar valiosa información sobre los corsarios españoles, quienes desde sus bases en Cuba, Puerto Rico, Campeche, Bacalar y Omoa combatían la navegación británica en la región del Golfo de Honduras. Cabe subrayar que el presente artículo constituye una aportación novedosa debido a que se desarrolla el aspecto del corso regional, hasta la fecha poco conocido, y que, sin embargo, fue un arma eficaz contra las transgresiones británicas.
\end{abstract}

Palabras clave: Corso español, contrabando, presas, Golfo de Honduras, siglo xviII.

ABSTRACT: The main objective of this article is the presentation of the corsair activities in the Gulf of Honduras between the years 1713 and 1763, the times when Great Britain received the privilege of trading with Hispano-America through the Asiento and the permission vessel. This event caused the development of contraband in different parts of the Greater Caribbean, such as the Atlantic coast of the General Captaincy of Guatemala. The problem was soon detected by metropolitan authorities, who rigorously began to combat illicit trade by granting Indian governors the power to issue corsair patents. Through the historiographic and archival studies it was possible to find valuable information about the Spanish corsairs, who from their bases in Cuba, Puerto Rico, Campeche, Bacalar and Omoa fought the British navigation in the region of the Gulf of Honduras. It should be emphasized that this article is an innovative contribution because it develops the aspect of the regional Corsair, so little known, and which was an effective weapon against the British transgressions.

${ }^{1}$ El artículo fue comentado en las reuniones de trabajo del grupo de investigación Estudios históricos de Chiapas, Centroamérica y el Caribe del CESMECA-UNICACH 
KEYwords: Spanish corsairs, smuggling, preys, Gulf of Honduras, 18th century.

ReCEPCIÓN: 15 de febrero de 2017.

ACEPTACIÓN: 27 de abril de 2017.

DOI: 10.19130/iifl.ecm.2018.51.884

El reinado de Carlos II (1665-1700), último monarca Habsburgo en el trono del Imperio español, se caracterizó por la crisis en los sectores económico, militar, administrativo y naval, tanto en la metrópoli como en Hispanoamérica. Esta grave situación se debió en primer lugar a la quiebra que dejó Felipe IV (1621-1665), rey que había intentado recuperar el esplendor de la monarquía hispana de su abuelo, Felipe II. Con ello involucró a la Corona en varios conflictos bélicos, donde las que más recursos monetarios consumieron fueron las guerras de los Treinta Años (1621-1648), las de independencia de Portugal (1640-1668) y Cataluña (1640-1652), y con la Inglaterra de Cromwell (1655-1660). Por otro lado, la escasa preparación de Carlos II y su discapacidad mental le convertían en una persona no apta para gobernar España. En este escenario se jugó la sobrevivencia de un vasto imperio, donde los españoles intentaron defender su posición como potencia mundial. Sin embargo, en el frente europeo la situación se dificultaba año tras año, Carlos II fue avergonzado por el rey Sol, Luis XIV de Francia, durante la guerra de Devolución (1667-1668). Por otro lado, en el frente americano los virreyes, gobernadores y alcaldes hispanos se encontraron con graves crisis, sobre todo en la cuenca del Gran Caribe, debido principalmente a que la piratería, desde sus bases en Jamaica, Tortuga y la parte noroccidental de La Española, se expandió prácticamente por toda el área del Golfo-Caribe, ${ }^{2}$ lo que provocó grandes desastres entre las poblaciones españolas: saqueos de ciudades como Veracruz, Campeche, Portobelo, Panamá, Cartagena de Indias, Trinidad (Cuba), Santiago de Cuba y Maracaibo, entre otras; disturbios en las comunicaciones circuncaribeñas y con la metrópoli y, finalmente, pérdidas económicas y comerciales nunca antes vistas.

Por ello, Mariana de Austria, la reina que gobernó en nombre de Carlos II entre 1665 y 1675, decidió tomar una decisión desesperada, y el 22 de febrero de 1674 aceptó la primera Ordenanza de corso para sus súbditos americanos (Barney, 1997: 357). Esta ley, que estuvo en vigor durante casi 150 años con pequeñas modificaciones $(1718,1762$ y 1779), fue un arma eficaz contra piratas, corsarios y contrabandistas ingleses, franceses y holandeses en el Gran Caribe. Cabe señalar que algunos investigadores como Jan Glete (2005), Jeremy Black (2009) e Iván Valdez Bubnov (2011) han estudiado la importancia de las estrategias de corso, que se desarrolló paralelamente con el crecimiento de las Marinas Reales europeas. Sin embargo, en el caso español, hasta la mitad del siglo xvII, el corso representaba para la monarquía un "mal menor", ya que desde la época de los reyes

\footnotetext{
${ }^{2}$ Los términos: Golfo-Caribe, Gran Caribe y Circuncaribe se refieren a la región que une el Golfo de México y el mar Caribe. Más información en Johanna von Grafenstein (1997).
} 
católicos tenía mala fama debido a que los corsarios extranjeros, sobre todo de Inglaterra, aprovechaban sus patentes para ejercer piratería, lo que transgredía el reglamento noble del corso. La oposición de Fernando e Isabel a la práctica de dicho oficio llegó a tal grado que, en 1489 , se prohibió por completo. El corso español implicó en los siglos posteriores situaciones similares de desgracia para la realeza, como ocurrió en 1652, cuando Felipe IV lo suspendió y decretó fuertes consecuencias penales para quienes lo ejercieran. No obstante, dicho oficio fue visible en la estrategia defensiva española desde la Edad Media, época en la que con frecuencia los monarcas expedían patentes para los hombres de mar y guerra del Cantábrico y del Mediterráneo (Lucena, 2006: 393-394).

Conviene aclarar que un corsario era un hombre de mar y guerra que, bajo la protección de una patente de corso expedida por el rey o las autoridades reales, atacaba, saqueaba o tomaba como presa a cualquier barco enemigo, en una guerra en la cual estaba involucrado su monarca. En cambio, un pirata no contaba con la protección real y actuaba contra todos los barcos y personas, a menudo de su propia nación, fuera de la ley (Azcárraga y Bustamante, 1950: 27-29).

La historiografía sobre el tema es vasta y en ella encontramos estudios y presentaciones del corso español, tanto peninsular como americano, de muy distinta índole. Dos obras clásicas que, entre otras, tocan este tema son Colección de los viajes y descubrimientos que hicieron por mar los españoles desde fines del siglo xv: con varios documentos inéditos concernientes a la historia de la marina castellana y de los establecimientos españoles en Indias, de Martín Fernández de Navarrete (1825-1837), e Historia de la Armada Española desde la unión de los reinos de Castilla y de Aragón, de Cesáreo Fernández Duro (1895-1903). En estas obras encontramos descripciones de acciones corsarias a lo largo del desarrollo de la marina española. Entre los autores contemporáneos destacan José Luis de Azcárraga y Bustamante (1950) y Enrique Otero Lana (2005, 2006 y 2009), en cuyos estudios exponen las raíces del corso hispano, reglamentos y derechos, además de las coyunturas que experimentó este oficio a lo largo de la historia. Otros autores como Manuel Lucena Salmoral (1992), Juan de Pérez Galaz (1992) y Cruz Apestegui Cardenal (2000), presentan el corso junto con la piratería, el filibusterismo y el bucanerismo. En cambio, Oscar Cruz Barney (1997, 2009 y 2013), en sus investigaciones sobre el corso se enfocó en los análisis jurídicos y el impacto que las ordenanzas de corso tuvieron en la sociedad americana. En cuanto a un enfoque regional del corso, no se han efectuado muchos trabajos al respecto. Un buen estudio sobre los corsarios españoles que actuaban en el estrecho de Gibraltar lo presenta Mario Ocaña Torres (1993), quien demuestra la determinación de la Corona para obstaculizar a los británicos en este punto tan importante estratégicamente. Por otro lado, sobre el corso en las Indias son interesantes las visiones de Victoria Stapells Johnson (1992) y Julio César Rodríguez Treviño (2013), quienes en sus aportaciones muestran la importancia de los corsarios en la defensa de los intereses de Santo Domingo y la isla La Española contra los contrabandistas, sobre todo de la nación francesa. Cabe señalar que el último autor también estudió a los corsarios en el 
Golfo de México y las hazañas de un corsario francés al servicio de España, Juan Chevallier, quien recibió una patente de corso del intendente de Yucatán Arturo O’Neill (Rodríguez, 2015). Otra área del Gran Caribe que se ha estudiado debido a su activa participación en la guerra de corso fue Cuba, donde Josefina Acosta de Para (2012) describe en su texto de divulgación científica las acciones más destacadas de los corsarios en la isla. Finalmente, cabe señalar otros tres trabajos que se han centrado en el estudio biográfico de los notables corsarios regionales. El primero, de Ángel López Cantos (1994), narra las hazañas del corsario puertorriqueño Miguel Enríquez, quien actuó en el siglo xvil en la defensa de la isla, pero también atacaba las posesiones extranjeras en las Antillas Menores. Las obras de Vicente de Amézaga Aresti (1966) y, una vez más, de Manuel Lucena Salmoral (2006), narran la historia del más famoso capitán corsario de la Compañía Guipuzcoana de Caracas, Vicente Antonio de Icuza, quien entre 1765 y 1779, al mando de la escuadra venezolana, capturó, echó a pique y obligó a varar en los bajos a 125 embarcaciones (Lucena, 2006: 409).

Esta breve revisión de las obras más importantes y novedosas de la historia del corso español aparentemente puede engañar por su abundancia, sin embargo, si nos centramos en el corso regional, nos damos cuenta de que en la misma cuenca grancaribeña faltan trabajos en los que se estudie a los hombres de mar y tierra de la región del Golfo de México, el Caribe neogranadino y panameño y, por supuesto, el Caribe centroamericano. Por otra parte, no se puede olvidar que las historiografías anglosajona, neerlandesa y francesa también han presentado valiosas investigaciones sobre los corsarios de dichas naciones.

En el presente artículo se muestran los primeros resultados de un trabajo historiográfico y archivístico realizado en España (Archivo General de Indias, Archivo del Museo Naval), México (Archivo General de la Nación) y Guatemala (Archivo General de Centroamérica), con el objetivo de describir al corso español y su lucha contra el contrabando en el Golfo-Caribe y en la Capitanía General de Guatemala, que se desató entre los años 1713 y 1763 . Un tiempo en que la región desarrolló un fructífero contrabando británico y holandés, lo que provocó fuertes represalias de la Corona hispana a través de la intensificación de las acciones corsarias, lo que a su vez dio pie a varios conflictos bélicos, que se desarrollaron entre el fin de la guerra de Sucesión Española (1713) y la paz de París, que finalizó la guerra de los Siete Años (1763).

Finalmente cabe subrayar que el estudio se centra en la presencia de los corsarios hispanos, provenientes de los puertos grancaribeños de Campeche, Bacalar, Golfo Dulce, Omoa, La Habana y Santiago de Cuba, quienes operaban en el área conocida como el Golfo de Honduras, la cual comprende la parte suroriental de la península de Yucatán, el Golfo Dulce y el litoral del Caribe hondureño y nicaraguiense hasta la Costa de los Mosquitos. La región presentaba inconvenientes y dificultades para la navegación de buques de mayor calado ya que estaba llena de peligrosos bajos y arrecifes que forman parte del sistema arrecifal mesoamericano. Estas condiciones geográficas facilitaban el ejercicio del contrabando, donde 
las pequeñas embarcaciones de los contrabandistas se escondían. En dicha área del Golfo de Honduras también se incluyen las islas de las Antillas Mayores, es decir, Cuba y Jamaica, debido a su gran influencia sobre la región de investigación.

\section{Situación económica y comercial de la Capitanía General de Guatemala}

Es interesante preguntarse por qué la Corona española no prestó atención al mercado centroamericano, el cual demostraba gran potencial para comerciar con bienes, tanto de importación como de exportación. Más aún, entre 1640 y 1740 la ruta marítima entre Sevilla o Cádiz y Trujillo, Puerto Caballos y Omoa, quedó prácticamente inutilizada. Los registros oficiales de los puertos hondureños mencionan tan solo 31 barcos metropolitanos; en cambio, en el mismo período partieron rumbo a la metrópoli 56 embarcaciones con productos centroamericanos (Santos, 1999: 465-466). Cabe decir que el Golfo de Honduras fue un mar difícil para la navegación a vela, como lo narra en una relación el capitán de fragata de la Marina española don Ignacio San Just, quien realizó un viaje en diciembre de 1751 desde La Habana hasta el Golfo Dulce vía las islas Guanajas, Trujillo, Puerto Caballos y Omoa. En su informe menciona que

la navegación en este seno es muy dificultosa a causa de los muchos bajos, cayos, islas, arrecifes, canales angostos, y fuertes corrientes que a veces tienen curso conocido y a veces no, porque cerca de los cayos, corren las aguas a embocar por sus canalizos con muchísima violencia, y si coge una embarcación en calma, la lleva a varar sobre sus arrecifes. ${ }^{3}$

Probablemente el peligro de encallar o naufragar influía en las decisiones de los capitanes de buques, que navegaban desde la metrópoli hacia el Gran Caribe para dirigirse a un puerto más seguro y allá realizar intercambio de cargamentos. Esa falta de una estable comunicación marítima con España, mediante la flotilla de Honduras o navíos de registro, provocó que los comerciantes centroamericanos buscaran otras vías para canalizar sus mercancías hacia Europa. Lo anterior dio lugar a que se crearan dos rutas alternativas para el transporte de bienes: la primera, por el camino real desde la ciudad de Santiago de Guatemala, vía la alcaldía mayor de Chiapa, a Oaxaca y después a Veracruz, y, la segunda, que utilizaba la navegación de cabotaje, a La Habana (Santos, 1999: 466).

Los sectores económicos más importantes de la Capitanía fueron la agricultura y la ganadería (Palma, 2006: 197). ${ }^{4}$ Las principales zonas donde se llevaban a cabo estas actividades se ubicaban en los territorios de las actuales Guatemala, Hon-

${ }^{3}$ AMN, Noticias Hidrográficas de América Septentrional, tomo 2, documento 8, foja 88v, 1752.

4 Éstas en su mayoría fueron utilizadas para el transporte por los caminos reales que conectaban Santiago de Guatemala con Oaxaca, con el Golfo Dulce y con Comayagua y Trujillo. Todavía en la década de 1760 se construyó un nuevo camino que conectaba la capital con Omoa. 
duras y Nicaragua. Sin embargo, también había regiones en las que se desarrollaban actividades artesanales, con centros productores en las alcaldías mayores de Chiapa, Totonicapán y Huehuetenango. En el valle de Metapas, en la alcaldía mayor de San Salvador, se extraía hierro para proveer al mercado interno del reino. Finalmente, en las zonas aledañas a Tegucigalpa, se explotaban minas de plata, las cuales tuvieron gran importancia en el desarrollo de la región, aunque, debido al difícil acceso a las vetas y a la lejanía de la Casa de la Moneda, que a partir de 1731 funcionaba en Santiago de Guatemala, no alcanzaron un gran desarrollo minero similar al del norte de Nueva España o al de Potosí, en el Perú (Patch, 1994: 92-101).

A lo largo de los siglos xvII y xvIII, el principal producto de exportación desde el reino fue el añil, alrededor del cual se levantó y fortaleció la economía de la Capitanía, pero también otros productos de la tierra como cochinilla, algodón, cacao, maderas tintóreas y duras, zarzaparrilla y, de vez en cuando, plata y oro jugaron cierto papel en el desarrollo económico y comercial. También se exportaban mulas y caballos hacia Nueva España, Cuba y Jamaica. En cambio, los géneros que absorbía el mercado interno de la Capitanía llegaban tanto de la metrópoli, como de ambos virreinatos. Los productos de mayor demanda fueron ropa y textiles, herramientas, hierro, bienes de casa y cocina, cera, plata, marroquinería, aceite, azúcar, tabaco, café, vino y aguardiente (Santos, 1999: 473-474).

Murdo MacLeod sostiene que los principales comerciantes de la región adecuaron el funcionamiento de sus negocios a la situación del mercado, de modo que tuvieron que utilizar varias vías alternativas para lograr ganancias. En el caso de las exportaciones, utilizaron como canales de distribución los puertos de Honduras, pero también los de Veracruz y La Habana, para tratar clandestinamente con los ingleses. Asimismo, para vender mercancías usaban sus asociaciones con funcionarios administrativos o desempeñaban algún puesto oficial que les garantizaba la comercialización de sus géneros a través del repartimiento y de ventas forzadas (MacLeod, 2008: 359-360). Por otro lado, José Manuel Santos Pérez llega a la conclusión de que todos los mercaderes guatemaltecos utilizaron conexiones familiares y a la administración colonial para alcanzar sus fines económicos y, al mismo tiempo, mejorar su posición social. Además, en varias ocasiones acudían a su poder político-administrativo para legalizar los efectos del contrabando con el fin de comercializarlos legalmente (Santos, 1999: 464-465).

\section{Causas del contrabando en el Reino de Guatemala. Algunos ejemplos}

Durante la crisis económica en el Reino de Guatemala, entre los años 1670 y 1690, provocada por la falta de atención de la metrópoli y por una estrategia comercial dirigida al aprovechamiento del potencial productivo y social de la Capitanía, resultó que el principal problema de ese estancamiento fue la falta de buenas rutas marítimas y terrestres para la exportación e importación de 
bienes. Ese potencial refleja claramente el origen del contrabando, el cual empujó al mercado del Reino de Guatemala hacia una nueva dinámica de desarrollo comercial estable y beneficioso para su sociedad. Los productos de la Capitanía que tuvieron mayor demanda en las actividades del contrabando fueron los colorantes, que se obtenían del añil y del palo de tinte. Especialmente el índigo tuvo un gran éxito en las transacciones con los tratantes ingleses y holandeses. A lo largo del siglo xviII, dicho tinte se producía a gran escala en la alcaldía mayor de San Salvador y después se enviaba hacia los puertos del Golfo de Honduras (MacLeod, 2008: 354-355).

Los contrabandistas españoles utilizaban sobre todo la ruta vía Tegucigalpa, donde todavía adquirían ciertas cantidades de plata y oro, para seguir hacia Olancho el Viejo y después rumbo a Trujillo, puerto que en aquellos tiempos estaba prácticamente abandonado. En una relación fechada el 12 de octubre de 1743, Lorenzo Herrera, comisario del partido de Olancho, reportaba al gobernador de Comayagua que desde hacía un tiempo había observado "el crecido número de tratantes y cargas de tinta añil que se enviaba a la costa para el trato ilícito por un camino nuevo que habían abierto [contrabandistas] por la montaña de Agalta en la jurisdicción del citado partido". ${ }^{5}$ En otro lugar de su memoria, el funcionario dijo que

llegando al pueblo Jano, un vecino le pasó la noticia que el día 15 de agosto por el camino a la montaña topó con cuatro o cinco trozos de recuas que se componían de más de 100 cargas de añil y las conducía un eclesiástico, don Miguel de Lardizaba, Simón de Figueroa, don Juan Valiente y un mulato de León, además otros españoles que no conocía, y que los demás eran indios y que iban al poblado Catacamas, en Olancho, para después seguir ruta hacia la villa inglesa situada en el río Tinto. ${ }^{6}$

Otro ejemplo es el caso de Joseph Herrera y Manuel Amatt, comerciantes de Santiago de Guatemala, quienes a bordo de su balandra traían 34 cajones de ropa fuera del registro que intentaban introducir a la Capitanía por el puerto de Omoa para venderla en la capital. En este caso es interesante destacar que los comerciantes tenían permiso para practicar el comercio con Cuba y, aprovechando su regreso de Santiago de Cuba, su embarcación arribó a la costa norte de Jamaica, donde los comerciantes adquirieron los 34 cajones con ropa inglesa (Reichert, 2012: 21).

Estos dos casos son sólo una pequeña muestra de los muchos actos de contrabando realizados por los propios súbditos del rey de España. Por eso fue tan importante llevar a cabo una lucha vigorosa contra el comercio ilícito en las Indias. El personaje más preocupado por el combate al contrabando fue el primer intendente de la marina española, José Patiño Rosales, quien al inicio de su labor

5 AGCA, A3.34 (4) Real Hacienda, Decomisos-Honduras, legajo 140, expediente 1293, foja 43, 1744.

${ }^{6}$ AGCA, A3.34 (4) Real Hacienda, Decomisos-Honduras, legajo 140, expediente 1293, foja 5, 1744. 
se enfocó en la restauración de la Marina Real y en la promoción del corso español, sobre todo en Hispanoamérica, lo que resultó un arma precisa y muy eficaz en la lucha contra el comercio clandestino.

\section{Noticias de la navegación europea y la vigilancia española en el Golfo de Honduras}

La tradición marítima en la región del Golfo de Honduras fue más regional que transatlántica, y en ella dominaba el cabotaje de embarcaciones de poco calado, tanto español como holandés e inglés. En el caso de los últimos, se formó una red de rutas que conectaban los establecimientos británicos de la Mosquitia, Roatán y Walis, principalmente con Jamaica y Caimanes, y ocasionalmente con los puertos de Boston, Filadelfia, Baltimore y Charleston, de los cuales recibían harina, herramienta, ropa, brandy y cera. En su retorno, los veleros de las colonias norteamericanas llevaban palo de Campeche y maderas duras (cedro y caoba). Además, los ingleses aprovechaban gran cantidad de islas, cayos, bancos, bahías y desembocaduras a lo largo de la península de Yucatán, desde el cabo Catoche hasta el Golfo Dulce, así como las islas de Guanaja, Roatán y Utila, y Cayos Cochinos en la costa de Honduras, para efectuar el contrabando de mercancías europeas y esclavos africanos, que intercambiaban sobre todo por añil, maderas y raramente oro.

Estas circunstancias provocaron que las autoridades españolas de las Capitanías de Yucatán, Cuba y Guatemala pusieran mayor cuidado en la vigilancia de los litorales del Golfo de Honduras. El liderazgo en la lucha contra comerciantes extranjeros clandestinos fue tomado por las autoridades de los puertos en La Habana, Trinidad, Santiago de Cuba y Baracoa, quienes expedían patentes de corso a partir de los años 1680 , forjando de esta manera la larga tradición del corso cubano en la región del Gran Caribe. Es interesante notar que los éxitos de capturar buen número de embarcaciones inglesas y neerlandesas por los armadores cubanos animó a partir de 1720 a dueños de buques de Campeche para perseguir y atacar a los barcos británicos que navegaban en las cercanías de los puertos de Campeche y Sisal, y desde el Cabo Catoche hasta el río Walis (Rubio, 1983: 322). Uno de más feroces enemigos británicos en Yucatán fue su gobernador, don Antonio de Figueroa y Silva, quien informó al rey que, en los primeros meses de 1731, los guardacostas campechanos apresaron ocho buques británicos cargados con palo de tinte; en cambio, los corsarios campechanos tomaron 18 embarcaciones de diferente calado donde "[h]allaron en ellas considerables porciones de bastimentos para los cortadores, quienes escarmentados de los continuos daños que se les hace se han ido retirando quedando solo en Walis unas pocas familias". ${ }^{7}$ Cabe subrayar que, durante los primeros 35 años del siglo xvIII, los corsarios de

${ }^{7}$ AGI, Audiencia de México, legajo 3162, fojas 11-12v, 1732. 
Campeche fueron muy activos militarmente. En ese tiempo perseguían y atacaban permanentemente a los cortadores madereros, tanto de la Laguna de Términos, que los españoles recuperaron completamente en 1717, como de Walis.

La estrategia de perseguir a los buques extranjeros en la zona entre Cuba, Yucatán y Cozumel también la realizó la Armada de Barlovento, empleando sus fuerzas contra los contrabandistas británicos, como sucedió en 1726, cuando don Rodrigo de Torres capturó entre las islas Cozumel y Mujeres varios buques ingleses (Reichert, 2012: 24).

Continuando con la causa corsaria, cabe señalar que los corsarios españoles no sólo vigilaban los mares y tomaban presas, sino también asaltaban las plantaciones británicas de Jamaica. Los españoles aprehendían allí esclavos negros, que después vendían en los puertos cubanos y La Española. Un ejemplo de ello es la acción del capitán corsario Francisco Cierto, quien el 12 de julio de 1747, con un bote armado para la guerra llamado Santa Rita, robó siete negros, dos negras y una cría. ${ }^{8}$

En la correspondencia oficial británica con frecuencia se señalaba la importancia de fortalecer la costa norte de Jamaica, que estaba más expuesta a las incursiones de corsarios españoles, y además se exigía el empleo de los privateers ingleses para asegurar las costas jamaiquinas y garantizar la seguridad de las plantaciones. El problema fue referido en una manera muy ilustrativa por el gobernador Edward Trelawny, quien durante su mandato avisó sobre los constantes ataques de los corsarios españoles a las plantaciones de Jamaica (Reichert, 2012: 25).

La constante amenaza y la violación de los acuerdos entre los súbditos de ambas Coronas llevaron a situaciones como la que ocurrió en enero de 1746, cuando desde Santiago de Cuba se vio una escuadra de seis buques corsarios ingleses integrada por un bergantín, dos paquebotes y tres balandras que estaban persiguiendo embarcaciones españolas y bloqueando el acceso al puerto. En esa ocasión los británicos intentaron capturar la fragata del capitán corsario Pedro de Garaicoechea, aunque sin éxito. Esta práctica, que consistía en formar pequeñas escuadras de entre cuatro y ocho barcos armados para bloquear los puertos cubanos y estorbar la navegación española en la región, era bastante frecuente. Sin embargo, los españoles siempre respondían con rapidez y eficacia, enviando sus corsarios y en ocasiones los buques de guerra de la Armada que estaban en el apostadero naval de La Habana. ${ }^{9}$

En muchas ocasiones se llegó a enfrentamientos feroces y sangrientos en los que los corsarios españoles, después de dar cañonazos, abordaban los buques enemigos y, en la mayoría de los casos estudiados, lograban combatir a sus rivales. Un ejemplo de esta táctica es la campaña del corsario cubano don Juan de Cañas, quien navegó bajo el permiso otorgado a la Compañía Real de La Habana. El 28 de agosto de 1745, con dos jabeques se dirigió a recorrer los cayos de la

${ }^{8}$ AGI, Audiencia de Santo Domingo, legajo 2170, foja 51v, 1747.

${ }_{9}^{9}$ AGI, Audiencia de Santo Domingo, legajo 2170, fojas 48-49, 1746. 


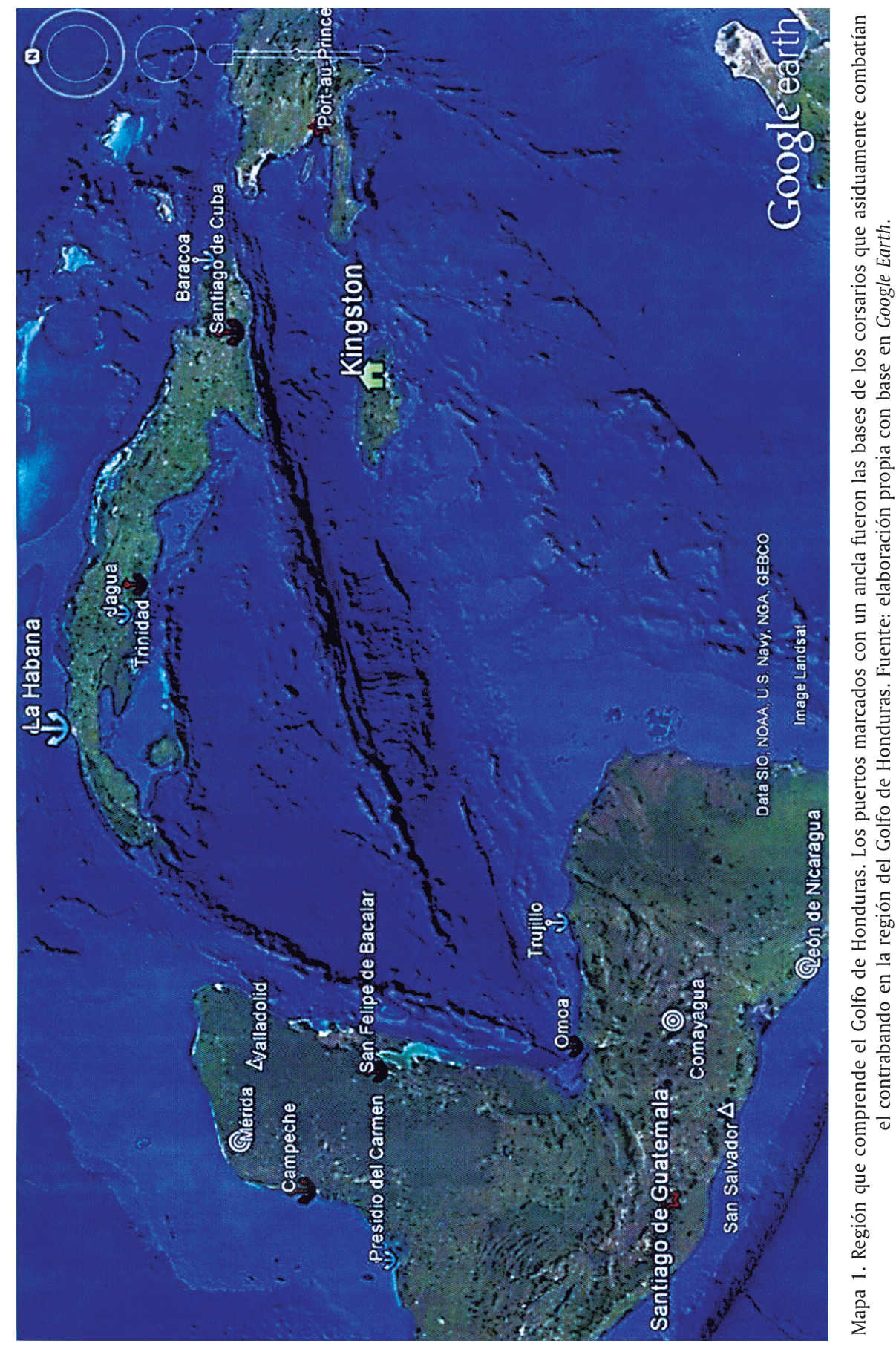


costa norte de Cuba para limpiarla de corsarios y contrabandistas enemigos y, no encontrándolos allá, puso proa hacia los cabos de Corrientes y San Antonio, para después ir al cabo de la Cruz, desde donde determinó poner proa a los bajos de la Víbora, paso obligado de los ingleses que navegaban hacia Jamaica. Después de una semana de navegación, cerca de puerto Savannah, en dicha isla, entró en combate con un paquebote guardacostas de Jamaica de 16 cañones. Estando a distancia proporcionada, los jabeques izaron su bandera, y lo mismo hizo el enemigo. El fuego de los cañones duró varias horas; sin embargo, ninguna de las partes cedió, por lo que don Juan de Cañas animó a su gente:

en nombre del rey exhortándoles con el honor de las armas y crédito de la nación para abordar al enemigo, con cuya voz y aliento se atracaron por popa y proa los dos jabeques con extraordinaria resolución y dándole a un mismo con los cañones de crujía por ambas partes facilitaron echarle a bordo como 200 hombres con sable y pistola en mano con tanta precipitación de los españoles que ninguno querría quedar a bordo de los jabeques y puestos los ingleses en la misma forma, duró el combate como dos horas. ${ }^{10}$

El capitán corsario informó que los ingleses mantuvieron "obstinada resistencia sobre cubiertas" y, obligados por los españoles, bajaron a la bodega, no obstante, no quisieron rendirse hasta que se hizo fuego contra ellos y les lanzaron granadas por las escotillas, lo que les "obligó a pedir buen cuartel y tomaron la decisión en que cedían ya sus fuerzas por los muchos muertos y heridos". En dicho enfrentamiento los ingleses perdieron 100 hombres, entre muertos y heridos graves, de los 136 que llevaba el paquebote. El capitán británico, que resultó herido en la cara, fue trasladado a bordo de la nave capitana y fue enviado, junto con la presa, al puerto de Jagua. Los españoles perdieron 20 hombres entre muertos y heridos de muerte; asimismo, un jabeque recibió graves daños en su cubierta. ${ }^{11}$

Es importante notar que entre los años 1713 y 1763, las hostilidades anglo-españolas siempre estuvieron presentes. De hecho, las fricciones entre ambas Coronas se desencadenaron en tres guerras: la de la Cuádruple Alianza (17171721), la Anglo-española (1727-1729) y la del Asiento (1739-1748), que también tuvieron como escenarios bélicos el Caribe y el Golfo de Honduras. En diciembre de 1752, Charles Knowles, gobernador de Jamaica, escribió en una carta que un vecino de Black River le dio noticia que había atrapado, en una emboscada, un bergantín corsario campechano que, con otros tres buques hispanos, persiguió y apresó varios barcos británicos en el Golfo de Honduras, entre la Costa de los Mosquitos y las islas Guanajas. Knowles decía que, desde el fin de la guerra del Asiento o de la Oreja de Jenkins, los corsarios españoles transgredían los acuerdos del tratado de Aquisgrán (1748) y seguían apresando embarcaciones inglesas en el Caribe y el Golfo de Honduras (Reichert, 2012: 26).

${ }^{10}$ AGI, Audiencia de Santo Domingo, legajo 2170, foja 40, 1745.

${ }^{11}$ AGI, Audiencia de Santo Domingo, legajo 2170, fojas 41v-42v, 1745. 


\section{Corsarios españoles en el Golfo de Honduras}

Para entender la necesidad de emplear a los corsarios en la región es menester presentar un breve estado de las defensas españolas que se encontraban en dicho territorio. El Reino de Guatemala, desde su establecimiento en 1540 hasta el fin de la guerra del Asiento (1748), fue considerado por las autoridades metropolitanas como una región secundaria en las estrategias defensivo-militares para las Indias, y especialmente para el Caribe. Cabe decir que, en la costa de dicho mar, que pertenecía a la Capitanía en ese tiempo, solamente se levantaron tres fortificaciones: la fortaleza Santa Bárbara (1550) en Trujillo, el castillo de San Felipe Lara (1595) en el Golfo Dulce y el castillo de la Inmaculada Concepción (1666) cerca de la desembocadura del río San Juan en el lago de Nicaragua. La única defensa que se levantó durante el gobierno de los Borbones fue la fortaleza de San Fernando (1752) en el puerto de Omoa. Se puede decir que, por esta razón, gran parte de la costa caribeña del reino quedaba indefensa, lo que a su vez facilitaba el acceso de los contrabandistas extranjeros a las zonas que se encontraban lejos de las capitales provinciales ubicadas más cerca de las costas pacíficas. Además, los comandantes y soldados de dichas plazas militares a menudo estaban involucrados en el proceder del comercio clandestino por falta de recursos económicos debido a los retrasos en sus sueldos y a la escasez de productos básicos.

Con ello, desde la apertura de los guardacostas y corsarios españoles en dicha región, a partir de la década de 1680, se valoró su gran importancia en el combate contra el contrabando tanto extranjero como español. Ello probablemente se debió a las buenas ganancias provenientes del remate de las presas, porque el armador solamente pagaba el quinto real y algunos impuestos, que en ocasiones se cancelaban para animar a los comerciantes a ejercer el corso. Seguramente este factor animaba a la gente para "aventurarse a la caza”.

En cuanto a los guardacostas, cabe decir que solamente se encontraban en las fortificaciones del Golfo Dulce y de Omoa. Según la relación de don Ignacio San Just, entre 1751 y 1752 , en el castillo de San Felipe Lara se utilizaba como guardacostas un jabeque, y en el castillo de San Fernando se encontraba una goleta al servicio de la vigilancia marítima. ${ }^{12}$ Sin embargo, la cantidad y el género de buques variaba de acuerdo con las necesidades y la solvencia de la Real Hacienda, la cual se encargaba de la manutención de dichas unidades. Sin embargo, por falta de tripulación, carena y recursos económicos, frecuentemente esos buques estaban inutilizados en sus apostaderos, como ocurrió en 1767, cuando quedaron inmovilizados cinco botes del castillo de San Felipe Lara ${ }^{13}$ y el bergantín San Fernando de la fortaleza de Omoa. ${ }^{14}$

\footnotetext{
12 AMN, Noticias Hidrográficas de América Septentrional, tomo 2, documento 8, fojas 87v y 91v,

13 AGCA, A2.1, Capitanía General, Asuntos generales, legajo 6770, expediente 11, foja 1, 1767.

${ }^{14}$ AGCA, A3.1, Real Hacienda, Asuntos generales, legajo 1930, expediente 30, foja 2, 1767.
} 1752. 
En ocasiones los gobernadores de las provincias de Nicaragua y Costa Rica también armaban bateles, bongos y piraguas para perseguir a los contrabandistas en las aguas bajo su jurisdicción. De hecho, en una relación de octubre de 1757, Melchor Vidal de Lorca y Villena, gobernador nicaragüiense, presentó una propuesta en la que mencionaba las embarcaciones más adecuadas para el combate contra el comercio ilícito. Según sus palabras,

en esta provincia y la de Costa Rica, son apropiadas unas piraguas grandes, bien armadas, para cuya construcción hay maderas muy apropósito en los montes inmediatos de este Lago de Nicaragua. Con la existencia de dichas embarcaciones no sólo se consiguiera perseguir contrabandistas, atacar zambos-mosquitos, sino también reconocer la costa y establecimientos de los ingleses en ella. ${ }^{15}$

Efectivamente, el tema de armar embarcaciones para asegurar dicha región no era nuevo ya que, dos años antes de la correspondencia citada, el gobernador de Costa Rica, Francisco Fernández de la Pastora, propuso construir

tres piraguas armadas, con 15 hombres cada una para evitar el comercio y trato ilícito, que la nación inglesa hace en el valle de Matina, quitando las vigías establecidas, por ser más perjudiciales que beneficiosas con cuyo costo y algo más pudieran mantenerse dichas embarcaciones y así mismo contener los indios zambos-mosquitos quienes roban los frutos de aquel país. ${ }^{16}$

Volviendo al tema de los corsarios, es notable que, en la información que se tiene sobre el corso en el Golfo de Honduras, se menciona que la mayoría de los buques que ejercían ese oficio provenían de fuera (La Habana, Santiago de Cuba, Trinidad, Campeche y Bacalar), hecho que se puede justificar solamente por la falta de recursos económicos para equipar un barco, ya que los lugareños del Golfo Dulce, Omoa y San Juan en varias ocasiones se alistaban para perseguir el comercio ilícito.

Entre los núcleos de los corsarios cubanos predominaban dos: el primero en La Habana, donde los hombres de mar y guerra se dieron a la tarea no sólo de atacar a los buques extranjeros en las cercanías de la isla, sino también en varias ocasiones se aventuraron hasta la altura de Nueva York y Rhode Island. Por ejemplo, durante la guerra del Asiento (1739-1748), en el litoral oriental de los actuales Estados Unidos actuaron Ignacio Olavarría, Domingo Coímbra, Andrés González y Juan Bustillos, todos provenientes del puerto habanero (Acosta, 2012). El segundo núcleo lo conformaban los corsarios santiaguenses, quienes preferían perseguir a los barcos extranjeros en las cercanías de su puerto, en el canal de los Vientos, por la costa sur de Cuba, por la costa norte de Jamaica y, como se ha mencionado, en la región del Golfo de Honduras. Cabe decir que dichos ma-

${ }^{15}$ AGI, Audiencia de Guatemala, legajo 874, foja 37v, 1757.

${ }^{16} \mathrm{AGI}$, Audiencia de Guatemala, legajo 874, foja 34, 1757. 
rineros tenían la capacidad de apresar en un corto plazo muchas embarcaciones, como ocurrió entre el 8 de junio y el 12 de octubre de 1747, cuando los santiaguenses, entre los cuales destacaban Pedro de Garaicoechea, Francisco Roldan, Manuel Bosque y Juan Bautista de la Mota, apresaron 45 embarcaciones de distintos tipos y con diferentes cargamentos. El corsario que realizó más intercepciones fue Garaicoechea, comandante de la fragata N. S. del Carmen, alias La Galga, quien logró 12 presas, de las cuales tres las capturó en las cercanías de la isla de Roatán. Dicho corsario llegó a ser tan famoso que las autoridades británicas de Jamaica organizaron varias "cacerías" para atraparlo, una de ellas cerca de Santiago de Cuba en enero de 1746; sin embargo, Garaicoechea, gracias a sus habilidades y conocimiento náutico, pudo escapar y arribar con tranquilidad a puerto. ${ }^{17}$ Llama la atención que, para no quedar presos, los ingleses en ocasiones abandonaban sus embarcaciones y se escondían tierra adentro. Un evento de estas características sucedió el 11 de septiembre de 1747 con una goleta que iba cargada de bacalao, barriles de macarelas, brea, alquitrán, duelas, tejamanil y algunas maderas como vergas y otros palos de embarcaciones, y que fue apresada por Juan Bautista de la Mota a bordo de su balandra de guerra a sotavento en la punta Morante de Jamaica. El capitán dijo que "no aprehend[ió] ningunos ingleses ya que vararon su buque y se echaron en tierra". ${ }^{18}$

Es interesante que las patentes de corso también se daban a los capitanes que navegaban desde la metrópoli a la región del Golfo Dulce. Un ejemplo de ello es el viaje que efectuó entre febrero y marzo de 1725 el capitán Martín de Bergara y Ortega, quien recibió permiso para atacar a todos los barcos enemigos que encontrara durante su navegación. De hecho, hizo presas entre Jamaica y Roatán. ${ }^{19}$ Otra manera de mantener la vigilancia en la región fue la invitación a corsarios o guardacostas de otros puertos para que vigilaran las costas caribeñas de la Capitanía. Eso sucedió con don Cosme de Sigarán, de La Habana, quien recibió la patente para poder "cazar" en el Golfo de Honduras; este corsario cobró cinco presas que llevó a Omoa. Por confusión de las autoridades, le quitaron sus capturas, pues habían cambiado al castellano del puerto y el nuevo no tenía comprobantes de su patente de corso. Sin embargo, el caso fue resuelto favorablemente, ya que el gobernador de La Habana, don Francisco Cagigal, expidió un oficio comprobatorio a la Audiencia de Guatemala que resolvió el 17 de julio de 1753 la devolución inmediata de todas las presas hechas por De Sigarán. ${ }^{20}$ Los desacuerdos sobre el mandato de las patentes de corso fueron evidentes en la región del Golfo de Honduras, como ocurrió en el caso de don Diego de Prado y don Francisco de Cáceres, corsarios de La Habana, quienes el 19 de noviembre de 1740 llegaron con su presa a Santo Tomás de Castilla, en el Golfo Dulce, donde

${ }^{17}$ AGI, Audiencia de Santo Domingo, legajo 2170, fojas 53-59, 1747.

${ }^{18}$ AGI, Audiencia de Santo Domingo, legajo 2170, fojas 57, 1747.

19 AGCA, A2.1, Capitanía General, Asuntos generales, legajo 2, expediente 32, foja 23, 1725.

${ }^{20}$ AGCA, A2.1, Capitanía General, Asuntos generales, legajo 31, expediente 1, fojas 1-15, 1753. 
se les decomisó junto con sus mercancías. Los cubanos tuvieron que reclamar su derecho mediante un juicio administrativo. En su caso, el pleito tardó casi dos años, ya que apenas el 15 de noviembre de 1742 se les otorgó un dictamen favorable y pudieron recuperar el valor de su presa, que las autoridades del Golfo Dulce ya habían vendido. ${ }^{21}$

Otro caso en el que se solicitó el servicio de corsarios foráneos es el del capitán don Gabriel Franco, quien en una goleta fue enviado por el marqués de Iscar, gobernador y capitán general de Yucatán, a patrullar las costas hondureñas y nicaragüenses bajo una patente expedida por el gobernador don Alonso de Heredia. Dicho corsario capturó su primera presa a finales de febrero de 1751, navegando todavía hacia el área de su operación, cuando tomó a la vista del río Walis una goletilla inglesa con nueve toneladas de palo de tinte. ${ }^{22}$ En cuanto a los corsarios campechanos, cabe decir que el primero que actuó en la región del actual Belice fue el capitán Esteban de la Barca, quien en agosto de 1722, al mando de dos piraguas armadas, subió por el río Walis y apresó una fragata cargada de palo de tinte con 36 ingleses y ocho negros. El corsario regresó a Campeche con su presa. Un año después el gobernador de Yucatán, don Antonio Cortaire, nuevamente otorgó patente a De la Barca, quien salió con una goleta, una piragua y 40 hombres. Durante la travesía desde Campeche hasta la bahía de Chetumal, el capitán aprehendió varias embarcaciones inglesas cargadas con palo de tinte. Al llegar a la desembocadura del río Walis quemó diversas rancherías británicas, en las cuales tomó presos y mercancías que llevó a su puerto de matrícula. ${ }^{23}$ Otro conocido corsario campechano que perseguía activamente a los extranjeros en la región de Walis y el Golfo Dulce fue Pedro Felipe de Sarriola, quien entre 1739 y 1745 capturó varias embarcaciones inglesas y holandesas. ${ }^{24}$ Finalmente, no se puede olvidar a los corsarios de Bacalar, quienes, impulsados por los gobernadores de Yucatán y con el visto bueno de los ministros de la Marina, el marqués de la Ensenada (1737-1754) y Julián de Arriaga (1754-1776), realizaron varias invasiones a los asentamientos británicos en Walis y apresaron embarcaciones cargadas de palo de tinte y maderas duras. Entre los años 1751 y 1758, fueron muy activos en la zona los capitanes Antonio Palma, Domingo Martín del Rosario y Pedro de la Puente. ${ }^{25}$ El primero de ellos, en junio de 1751, al mando de siete piraguas armadas en los ríos Hondo y Walis, capturó y quemó 43 embarcaciones de diferentes tamaños que transportaban palo de Campeche (Conover, 2013: 61-63).

A pesar de la escasa información que se tiene sobre los corsarios matriculados en los parajes del Golfo de Honduras, pueden encontrarse personajes que se ocuparon de dicho oficio en el área. Uno de ellos fue Joseph Rejón de Silva,

${ }^{21}$ AGCA, A3.6, Real Hacienda, Comercio y marina, legajo 77, expediente 1529, fs. 1-27, 1742.

22 AGI, Audiencia de Guatemala, legajo 884, foja 14, 1751.

${ }^{23}$ AGN, Reales Cédulas Originales, volumen 44, expediente125, fojas 237-242, 1724.

${ }^{24}$ AGI, Audiencia de México, legajo 1015, fojas 29-33v, 1745.

${ }^{25}$ AGI, Audiencia de México, legajo 1027, fojas 41-42v, 1758. 
quien al mando de dos piraguas navegó por la costa hondureña, donde atrapó varias embarcaciones, entre ellas, en abril de 1749 , un bergantín inglés nuevo que desmanteló y del que aprovechó su velamen, aparejo y algunas maderas para terminar una goleta guardacostas que estaba armando en la desembocadura del río Motagua el gobernador de Honduras, don Alonso de Heredia. ${ }^{26} \mathrm{Al}$ mismo tiempo, el oficial real dio patente a don Francisco Mateo de la Guerra y a su socio don Juan de Vera, quienes armaron por su propia cuenta una goleta corsaria en Omoa. Su primera presa, que encontraron el 30 de marzo de 1750, fue la balandra El Próspero, de 50 toneladas, anclada en el paraje de Gracias a Dios. Su capitán, Simón Walton, abrió fuego sobre la bandera de Su Majestad y empezó un combate en el que dicho corsario perdió cinco hombres, y el inglés siete. Finalmente, al tomar el buque se lo declaró buena presa. ${ }^{27}$ También en la misma época actuó otro corsario hondureño, el capitán Felipe López, quien se dio a la labor de pelear contra los ingleses y zambos-mosquitos asentados en el río Tinto y el Cabo Gracias a Dios. Con su piragua armada realizó asaltos a dichas poblaciones y tomó por sorpresa a dos balandras que descargaban mercancías en la costa. ${ }^{28}$

Sin embargo, el más conocido corsario del Golfo de Honduras fue don Joseph de Palma, el capitán del bergantín llamado San Joseph, matriculado en Omoa, quien en múltiples ocasiones realizó patrullajes entre dicho puerto y la desembocadura del río Matina. En la segunda mitad de 1756, en dicha zona apresó tres embarcaciones inglesas: la balandra La Expedición, que iba de Walis a Jamaica con cargamento de palo de tinte; otra balandra llamada Hibernian, que fue tomada en el crucero de Trujillo para la Guanaja, con cargamento de palo de tinte, tablones de caoba y carey, en su viaje de Walis a Jamaica, y el bergantín Roberto, que fue reconocido y apresado 17 leguas al nordeste y 4 leguas al este de la isla de Santanilla, con cargamento de palo de tinte y 59 tablones de caoba, que cargó en el paraje del río Tinto. El comandante del bergantín, Thomas Bonville, al ser entrevistado por Joseph de Palma, dijo que "los ingleses en las poblaciones del río Tinto tenían permiso para mantenerse en esta región con el permiso de su majestad británica". Asimismo, comunicó que "el cargamento más común que trafican embarcaciones inglesas a aquel Puerto [río Tinto] es todo género de lencerías, algunas lanas y comestibles, y que la carga con que retornan es caobana y Carey". ${ }^{29}$ Las tomas que el corsario realizó causaron tanta rabia entre los británicos que el 10 de enero de 1757 el gobernador de Jamaica, don Enrique Moore, escribió lo siguiente al capitán general de Guatemala, Alonso de Arcos y Moreno:

[...] varios bajeles han sido cogidos por un corsario español comandado por don Joseph de Palma y como estoy informado han sido llevados al puerto de Omoa, en procedimiento de esta naturaleza en tiempo de paz, es preciso [que] lleve consigo

${ }^{26}$ AGI, Audiencia de Guatemala, legajo 884, fojas 5-7v, 1749.

${ }^{27}$ AGI, Audiencia de Guatemala, legajo 884, fojas 8-11, 1750.

${ }^{28}$ AGI, Audiencia de México, legajo 3099, fojas 92-97, 1752.

${ }^{29} \mathrm{AGI}$, Audiencia de Guatemala, legajo 884, fojas 21-28v, 1756. 
un aspecto poco favorable y no se puede mirar en otra luz en la opinión de los que no son apasionados, sino como un acto de Piratería que estoy asegurado [que] ha de estar V.S. muy lejos de condescender en ninguna manera por lo que me precisa imaginar que estas irregularidades han sido cometidas sin vuestra privanza y consentimiento. ${ }^{30}$

El gobernador de Guatemala respondió que averiguaría sobre el caso pero, con aprobación del ministro de Marina, Julián de Arriaga, nunca se castigó al corsario y tampoco se devolvieron las presas hechas por él. Sin embargo, la represalia británica afectó al departamento naval de La Habana, el cual tenía acuerdo con el gobernador de Jamaica para comprar 100 negros para las obras del arsenal; con lo cual, el contrato fue cancelado. Por ello, el jefe de la escuadra, Blas de Barreda, mandó una carta de protesta al capitán general de Guatemala, Alonso de Arcos y Moreno, para que castigara al armador don Joseph de Palma, hecho que nunca sucedió. ${ }^{31}$

\section{Conclusiones}

El presente artículo es resultado de una investigación que el autor ha desarrollado sobre el contrabando en la región caribeña de la Capitanía General de Guatemala en el siglo xviII. El tema del corso español está presente en la documentación histórica o, mejor dicho, aparece con igual frecuencia que los juicios y decomisos del comercio clandestino, por eso, tras recopilar la información archivística y bibliográfica, ha sido posible presentar algunos aspectos de esta arma utilizada por las autoridades, tanto metropolitanas como indianas, para hacer frente al diluvio de mercancías ilícitas que, a partir del cambio dinástico en el trono de España, causaron un gran dolor de cabeza a la Corona. Los ministros de la Marina José Patiño (1717-1736), el marqués de la Ensenada (1737-1754) y Julián de Arriaga (1754-1776) prestaron mucha atención al combate del contrabando en las Indias, y con entusiasmo apoyaron las acciones corsarias facilitando el proceso de armar buques, creando las reales compañías (de Caracas en 1728 y de La Habana en 1740) y garantizando buenos beneficios al vender sus presas. Esta política fue un éxito, ya que liberaba a la Marina de la persecución del comercio clandestino y no implicaba grandes costos para el real erario. Sin embargo, las numerosas capturas y los encuentros bélicos en el mar dieron pie a constantes quejas de los embajadores, tanto en Madrid como en Londres, en contra de la violación de los acuerdos de paz y colaboración entre las naciones española y británica. Las interminables fricciones por los intereses geopolíticos, mercantiles y de navegación en América entre ambas Coronas involucraban de forma permanente a los colonos de uno u otro país en los conflictos bélicos regionales e internacionales (guerras de la

\footnotetext{
${ }^{30}$ AGI, Audiencia de Guatemala, legajo 884, fojas 30-31v, 1757.

${ }^{31}$ AGI, Audiencia de Guatemala, legajo 884, fojas 32-33v, 1758.
} 
Cuádruple Alianza, Anglo-española, del Asiento y de los Siete Años), conflictos que, por primera vez en la historia, también dejaron su huella en la región del Golfo de Honduras, que se convirtió en uno de los principales escenarios de guerra en las Indias del siglo xviII.

Cabe decir que, en este momento del desarrollo de la investigación, no ha sido posible cuantificar las presas y su valor debido a que la información es muy dispersa y faltan los datos consecutivos; por el contrario, en el caso de los corsarios cubanos, los documentos ofrecen mayores detalles. Sin embargo, a partir de los datos estudiados se puede decir que entre 1713 y 1763 la región del Golfo de Honduras fue atractiva para los corsarios españoles, tanto lugareños como de otros puertos grancaribeños (Campeche, San Felipe de Bacalar, La Habana, Santiago de Cuba, Trinidad). Es verdad que la mayor intensificación de la guerra de corso se produjo entre 1740 y 1750, cuando los españoles vivieron tiempos de bonanza. Un dato interesante lo aporta un folleto sobre las presas y sus valores realizado para el público metropolitano, en especial para el duque de Montemar. En dicho folleto se recogieron los sucesos ocurridos entre el 19 de octubre de 1739 y el 1 o de enero de 1741 , cuando los corsarios españoles, tanto de las Indias como de España, apresaron 407 embarcaciones inglesas por un valor de 3850300 pesos de a ocho reales. ${ }^{32}$ Las presas incluían la carga y los esclavos, pero también el barco; todas estas mercancías se ponían a la venta y las dos terceras partes de lo obtenido quedaban en los bolsillos del armador corsario y de su gente de mar y guerra. En el caso de las capturas hechas en el Golfo de Honduras, el promedio de la carga era de alrededor de 8000 pesos de a ocho, más lo que aportaba la embarcación contrabandista, cuyo precio dependía del tamaño de la unidad y de su estado. Sin embargo, hubo casos en los cuales los corsarios ganaban una fortuna, como sucedió el 7 de noviembre de 1742, cuando el corsario habanero Antonio Chaulier capturó un bergantín y una balandra cerca de Jamaica con un cargamento de casi 70000 pesos en oro y plata, además de otras mercancías y esclavos. ${ }^{33}$

Quizá el corso español en las Indias, y sobre todo en la región del Golfo de Honduras, no acabó con el proceder del contrabando; no obstante, influyó en su disminución y provocó el pánico entre los extranjeros, quienes comerciaban bajo una fuerte presión y con miedo de caer presos en cualquier momento. Asimismo, los hombres de mar y guerra que defendían los intereses de la Corona no sólo se ocupaban de la captura de contrabandistas, sino también de hostilizar a las posesiones enemigas, y sobre todo del combate naval, en el que los españoles demostraban un gran valor al abordar los barcos corsarios ingleses y holandeses. En otros casos, algunos corsarios americanos se convirtieron en leyendas vivas y temibles, como Miguel Henríquez (corsario puertorriqueño), Pedro de Garaicoechea (santiaguense) y Vicente de Icuza (caraqueño).

\footnotetext{
32 BNE, Manuscritos, signatura P.V. 4, expediente 12766.

33 AGI, Audiencia de Santo Domingo, legajo 2167, fojas 71-72, 1742.
} 
Finalmente, es importante señalar que el corso español en el siglo xvIII, por su gran utilidad, evolucionó en la percepción de los oficiales reales de considerarse un "mal menor" a un oficio prestigioso, de manera que los corsarios llegaron a gozar de los mismos privilegios que los marinos reales, con su fuero y prestaciones. Ello, más la aventura y buena ganancia, hicieron que dicha actividad atrajera a muchos criollos al servicio corsario. De hecho, el aspecto social de la vida corsaria deja un gran campo de preguntas a resolver, como, por ejemplo, ¿quiénes integraban la tripulación y cómo se organizaban?, ¿qué estatuto tuvieron los corsarios en las sociedades portuarias del Golfo de Honduras?, ¿los mulatos e indígenas formaban parte de las tripulaciones?, y aunque en este momento de la investigación no es posible dar una buena respuesta a dichas cuestiones, seguramente serán atendidas en futuras aportaciones sobre el corso español del Golfo de Honduras.

\section{Bibliografía}

Acosta de Para, Josefina

2012 "Corsarios criollos", <http://www.uvsfajardo.sld.cu/corsarios-criollos > [Consultado el 29 de octubre de 2016].

Amézaga Aresti, Vicente de

1966 Vicente Antonio de Icuza, Comandante de Corsarios. Caracas: Comisión Nacional de Cuatricentenario de Caracas.

Apestegui Cardenal, Cruz

2000 Los ladrones del mar: Piratas en el Caribe. Corsarios, filibusteros y bucaneros 1493-1700. Barcelona: Lunwerg Editores.

Azcárraga y Bustamante, José Luis de

1950 El corso marítimo. Madrid: Consejo Superior de Investigaciones Científicas.

Black, Jeremy

2009 Naval Power. A History of Warfare and the Sea from 1500. London: Palgrave Macmillan.

Conover Blancas, Carlos

2013 "Llave y custodia de esta provincia. El presidio de San Felipe Bacalar ante los asentamientos británicos del Walix. 1779-1798”, tesis de maestría en Historia. México: Universidad Nacional Autónoma de México, Facultad de Filosofía y Letras.

Cruz Barney, Oscar

1997 El régimen jurídico del corso marítimo: el mundo indiano y el México del siglo XIX. México: Universidad Nacional Autónoma de México, Instituto de Investigaciones Jurídicas. 
2009 El corso marítimo. Influencias de la Ordonnance de la Marine de 1681 en el derecho hispano-indiano. México: Universidad Nacional Autónoma de México, Instituto de Investigaciones Jurídicas.

2013 El corso marítimo. México: Secretaría de Marina, Universidad Nacional Autónoma de México, Instituto de Investigaciones Jurídicas.

Fernández de Navarrete, Martín

$1825 \quad$ Colección de los viajes y descubrimientos que hicieron por mar los españoles desde

-1837 fines del siglo Xv: con varios documentos inéditos concernientes a la historia de la marina castellana y de los establecimientos españoles en Indias. Madrid: Imprenta Real, $\mathrm{V}$ tomos.

Fernández Duro, Cesáreo

1895 Historia de la Armada Española desde la unión de los reinos de Castilla y de Ara-1903 gón. Madrid: Imprenta Real, IX tomos.

Glete, Jan

2005 Naval History 1500-1680. Oxford: Routledge.

Grafenstein, Johanna von

1997 Nueva España en el Circuncaribe, 1779-1808. Revolución, competencia imperial y vínculos intercoloniales. México: Universidad Nacional Autónoma de México, Centro Coordinador y Difusor de Estudios Latinoamericanos.

López Cantos, Ángel

1994 Miguel Enríquez, corsario boricua del siglo XVIII. San Juan: Ediciones Puerto.

Lucena Salmoral, Manuel

1992 Piratas, bucaneros, filibusteros y corsarios en América. Madrid: Mapfre.

2006 "Vicente Antonio de Icuza y el noble oficio de corsario español", Itsas Memoria. Revista de Estudios Marítimos del País Vasco, 5, 393-413.

MacLeod, Murdo

2008 Spanish Central America: A Socioeconomic History, 1520-1720. Austin: University of Texas Press.

Ocaña Torres, Mario

1993 El corso marítimo en el estrecho de Gibraltar (1700-1802). Cádiz: Instituto de Estudios Campogibraltareños.

Otero Lana, Enrique

2005 "El corso del Flandes español como factor de guerra económica", Studia Historica. Historia moderna, 27: 111-133.

2006 "Los corsarios vascos en la Edad Moderna”, Itsas Memoria: Revista de Estudios Marítimos del País Vasco, 5: 193-227.

2009 "El corso en las Islas Canarias durante la Guerra de la Oreja de Jenkins (1739-1748)", Anuario de Estudios Atlánticos, 55: 117-142. 
Palma Murga, Gustavo

2006 "Caminos y veredas en la Guatemala colonial. Frágiles, permanentes y eficaces mecanismos de articulación humana y económica al mundo de esa época”, Rutas de la Nueva España, pp. 177-207, Ch. Cramaussel (ed.). Zamora: El Colegio de Michoacán.

Patch, Robert

1994 "Imperial Politics and Local Economy in Colonial Central America, 16701770", Past and Present, 143: 77-107.

Pérez Galaz, Juan de

1992 Piratas y corsarios en los mares de México y del mundo. México: Panorama.

Reichert, Rafal

2012 "Navegación, comercio y guerra, rivalidad por el dominio colonial en la región del Golfo de Honduras, 1713-1763”, Península, 7 (1): 13-38.

Rodríguez Treviño, Julio César

2013 "La organización jurídica, económica y social del corso español en la isla de Santo Domingo: su uso en el siglo XVIII para perseguir el comercio ilícito", Ulúa, 22: 11-44.

2015 "La red del corsario francés Juan de Chevalier y sus presas angloamericanas en el Caribe durante las Guerras Navales (1796-1808)", América Latina en la Historia Económica, 22 (1): 115-149.

Rubio Mañé, José Ignacio

1983 El virreinato III, expansión y defensa. México: Fondo de Cultura Económica, Universidad Nacional Autónoma de México.

Santos Pérez, José Manuel

1999 "Los comerciantes de Guatemala y la economía de Centroamérica en la primera mitad del siglo xvıII", Anuario de Estudios Americanos, 56 (2): 463-484.

Stapells Johnson, Victoria

1992 Los corsarios de Santo Domingo, 1718-1779: un estudio socio-económico. Lleida: Universidad de Lleida.

Valdez-Bubnov, Iván

2011 Poder naval y modernización del estado. Política de construcción naval española (XVI-XVIII). México: Universidad Nacional Autónoma de México, Instituto de Investigaciones Históricas.

\section{Documentos de archivo}

ARCHIVO GENERAL DE CENTROAMÉRICA (AGCA)

Ciudad de Guatemala, Guatemala

AGCA, A2.1, Capitanía General, Asuntos generales, legajos 2 exp. 32, f. 23, 8 de febrero de 1725, "Se otorga patente de Capitán de fragata a don Martín de Bergara y Ortega, 
con facultad de que ejerza el corso contra navíos de piratas, durante su carrera entre España y puertos del Golfo Dulce".

AGCA, A2.1, Capitanía General, Asuntos generales, legajo 31 exp. 1, fs. 1-15, 17 de julio de 1753, "Actas sobre las cinco presas que se han quitado en el puerto de Omoa al capitán corsario, don Cosme de Sigarán...".

AGCA, A2.1, Capitanía General, Asuntos generales, legajo 6770, exp. 11, foja 1, 4 de octubre de 1767. "Don Joaquín de Ibarra, castellano y alcalde del castillo de San Felipe del Golfo, pide la reparación de los cinco botes armados, encargados de la persecución de contrabandistas y piratas".

AGCA, A3.1, Real Hacienda, Asuntos generales, legajo 1930 exp. 30, foja 2, 25 de abril de 1767. "Cuenta de lo gastado en el mantenimiento del bergantín guardacostas del puerto de Omoa, nombrado San Fernando".

AGCA, A3.34 (4) Real Hacienda, Decomisos-Honduras, legajo140, exp. 1293, 43ff, 12 de febrero de 1744, "Testimonio de los autos hechos sobre embarazar el ilícito comercio con los enemigos de la Real Corona y providencias generales y particulares que se han dado...".

AGCA, A3.34 (4) Real Hacienda, Decomisos-Honduras, legajo 2869 exp. 41779, fs.1-56v. 22 de febrero de 1758, "Diligencias sobre el decomiso de 34 cajones de géneros de ilícito comercio introducidos en este Reino por don Joseph de Herrera".

AGCA, A3.6, Real Hacienda, Comercio y marina, legajo 77 exp. 1529, fs. 1-27, 15 de noviembre de 1742, "Los Oficiales Reales de Guatemala, en carta de primero de diciembre de 1740 dieron avisos al Gobernador y Capitán General de Cuba, sobre el decomiso de los géneros que conducía la balandra armada en corso al cargo de don Diego de Prado y don Francisco de Cáceres...".

ARCHIVO GENERAL DE INDIAS (AGI)

Sevilla, España

AGI, Audiencia de Guatemala, legajo 874, f. 33-38v, 1 de octubre de 1757, "Informes sobre las correrías de los Zambos Mosquitos y proposición de providencias para contenerlos y escarmentarlos".

AGI, Audiencia de Guatemala, legajo 884, fs. 5-7v, 20 de abril de 1749, "Don Joseph Rejón de Silva da cuenta de haberse apresado con un tercer armamento que hizo de dos piraguas, un bergantín inglés que andaba en las costas de Honduras".

AGI, Audiencia de Guatemala, legajo 884, fs. 8-11, 22 de septiembre de 1750, "Consecuente a la presa hecha por don Francisco Matheo de la Guerra, de la balandra inglesa nombrada 'el Prospero' tomada 30 de marzo".

AGI, Audiencia de Guatemala, legajo 884, f. 14, 4 de marzo de 1751, "Participa que la galera que se le envió de Campeche apresó a la vista del rio Walis una goletilla inglesa con nueve toneladas de palo de tinte, con que hacia viaje a sus colonias, sin que llevasen otros géneros".

AGI, Audiencia de Guatemala, legajo 884, fs. 21-28v, 31 de diciembre de 1756, "El presidente de Audiencia de Guatemala, don Alonso de Arcos y Moreno, da cuenta con testimonio de las diligencias practicadas en virtud de las dos presas de las balandras inglesas nombradas Hibernian y Roberto que apresó do Joseph de Palma”.

AGI, Audiencia de Guatemala, legajo 884, fs. 30-31v, 10 de enero de 1757, "Copia de carta que escribió el gobernador de Jamaica y su respuesta sobre quejas contra el armador don Joseph de Palma por haber apresado tres embarcaciones inglesas". 
AGI, Audiencia de Guatemala, legajo 884, fs. 32-33v, 26 de mayo de 1758, "Carta de don Blas de Barreda, jefe de escuadra en el departamento de La Habana en que me dice que el gobernador de Jamaica le escribió quejándose de que yo no le respondía a la que me remitió contra corsario don Joseph de Palma...”.

AGI, Audiencia de México, legajo 1015, fs. 29-33v, 7 de octubre de 1745, "Carta del gobernador de Yucatán, don Antonio Benavides Bazán y Molina sobre las andanzas del capitán, Pedro Felipe de Sarriola, en la persecución de comercio inglés".

AGI, Audiencia de México, legajo 1027, fs. 41-42v, 20 de mayo de 1758, "Informe del gobernador y capitán general de Yucatán, don Melchor de Navarrete, sobre los corsarios de San Felipe de Bacalar".

AGI, Audiencia de México, legajo 3099, fs. 56-58v, 12 de septiembre de 1751, "Carta del gobernador y capitán general de Yucatán, don Juan José de Clou, sobre el ataque del capitán corsario, don Josef Antonio Palma a Walis y río Hondo".

AGI, Audiencia de México, legajo 3099, fs. 92-97, 19 de febrero de 1752, "Informe del capitán corsario, don Felipe López sobre presas que ha hecho a los ingleses de Cabo de Gracias a Dios y Río Tinto".

AGI, Audiencia de México, legajo 3162, fojas 11-12v, 2 de abril de 1732 "Informe del capitán general de Yucatán, don Antonio de Figueroa y Silva sobre las presas hechas por guardacostas de Campeche...".

AGI, Audiencia de Santo Domingo, legajo 2167, f. 71-72, 18 de diciembre de 1742, "En carta de 18 de diciembre próximo pasado da V.S. cuenta de que entró a este Puerto [de La Habana] la fragata corsaria del cargo de capitán, don Antonio Chaulier con la presa de un bergantín y una balandra...”.

AGI, Audiencia de Santo Domingo, legajo 2170, fojas 48-49, 21 de enero de 1746, "Informe del gobernador de La Habana, don Diego Peñalosa, sobre andanzas del enemigo ingles en la costa sur de esta isla".

AGI, Audiencia de Santo Domingo, legajo 2170, foja 51v, 19 de octubre de 1747, "Carta dirigida al Marqués de la Ensenada, del gobernador de La Habana, don Francisco Antonio Cagigal de la Vega, sobre los sucesos de corsarios cubanos contra los ingleses".

AGI, Audiencia de Santo Domingo, legajo 2170, fs. 53-59, 19 de octubre de 1747, "Carta dirigida al Marqués de la Ensenada, del gobernador de La Habana, don Francisco Antonio Cagigal de la Vega, sobre los sucesos de corsarios...".

\section{ARCHIVO GENERAL DE LA NACIÓN (AGN)}

Ciudad de México, México

AGNM, Reales Cédulas Originales, vol. 44, exp.125, fs. 237-242, 12 de diciembre de 1724, "Informe del gobernador y capitán general de Yucatán, don Antonio Cortaire sobre las expediciones del capitán, don Esteban de la Barca contra los ingleses de dicha provincia".

ARCHIVO DEL MUSEO NAVAL (AMN)

Madrid, España

AMN, Noticias Hidrográficas de América Septentrional, tomo 2, doc. 8, fs. 87v-91v, 4 de julio de 1752, "Relación de varias noticias del Seno de Honduras adquiridas en el viaje que hizo capitán de fragata don Ignacio San Just a ese seno con la fragata de su mando, nombrada la Flora, desde el puerto de La Habana...”. 
BIBLIOTECA NACIONAL DE ESPAÑA (BNE)

Madrid, España

BNE, Manuscritos, signatura P.V. 4, exp. 12766, "Papel nuevo en que se hace manifiesto al público en una puntual y verídica relación [de] todas las presas que han hecho los armadores españoles desde que se publicó la guerra con Inglaterra hasta primero de enero de este presente año de $1741 \ldots$... 